\title{
NIEVE Y RIESGO DE ALUDES EN LA MONTANAA CANTÁBRICA: EL ALUD DE CARDAÑO DE ARRIBA, ALTO CARRIÓN (PALENCIA)
}

\author{
Enrique SERRANO CAÑADAS (serranoe@fyl.uva.es) \\ PANGEA, Departamento de Geografía, Universidad de Valladolid. \\ Manuel GÓMEZ LENDE (manuelglende@hotmail.com) \\ PANGEA, Departamento de Geografía, Universidad de Valladolid. \\ Alfonso PISABARRO PÉREZ (pisabarro@gmail.com) \\ PANGEA, Departamento de Geografía, Universidad de Valladolid.
}

Recibido: $26 / 12 / 2015$

Aceptado: 20/03/2016

RESUMEN: Los aludes son un elemento primordial de la montaña cantábrica invernal, pero pese a ello, existen pocos estudios sobre la nieve y los aludes. Diferentes figuras de ordenación de Castilla y León consideran la nieve como un recurso y como un riesgo, pero se han realizado pocas iniciativas reales relativas a riesgos nivales hasta este momento. En este trabajo se estudia el alud de Cardaño de Arriba. El método se ha basado en el trabajo de campo y la fotointerpretación para determinar la procedencia, cantidad de nieve movilizada y los daños causados en el medio natural y sobre las infraestructuras. Se ha considerado el volumen, peso de la nieve, geometría, presión de impacto estimada y velocidad estimada como aproximación a la capacidad de transporte y al potencial de daños del alud. El alud tuvo lugar entre el 9 y el 13 de febrero, cuando espesores de nieve $>2 \mathrm{~m}$ propiciaron la inestabilidad del manto nival. Se generó un alud de placa y de flujo seco que descendió desde laderas con pendientes de $36,5^{\circ}$ a una altitud 1900-2070 m hasta $1415 \mathrm{~m}$. Movilizó $51000 \mathrm{~m}^{3}$, desplazados a una velocidad estimada de 20,5/29,8 $\mathrm{m} \mathrm{s}^{-1}$ que ejercieron una presión de impacto estimada entre 10,2 y 20,8 $\mathrm{kg} / \mathrm{m}^{2}$. La masa de nieve causó daños en el fondo de valle, el principal la destrucción total del refugio del Club Espigüete, pero también daños en el camino rural, en el tejado de la iglesia, en el arbolado de la vega, rotura de postes y cables de la luz, y derrumbe de un muro. La importancia de los aludes aconseja realizar estudios detallados sobre riesgo de aludes y una gestión del territorio para la mitigación del riesgo sensible al conocimiento tradicional y científico de la nieve y los aludes.

PALABRAS CLAVE: aludes, riesgos, geomorfología, Montaña Cantábrica.

SNOW AND AVALANCHES RISK IN THE CANTABRIAN MOUNTAINS: THE SNOWAVALANCHE OF CARDAÑO DE ARRIBA, UPPER CARRIÓN, (PALENCIA)

ABSTRACT: The snow avalanches are a main element of the wintry Cantabrian Mountains, although there are few struries on snow and avalanches. Several territorial management regulations of Castilla y León Region considerate the snow as a resource and a natural risk, but not 
much initiatives have been made until now related to the snow risks. In this work are studied the snow avalanche which occurred in the Cardaño valley, reaching the village of Cardaño de Arriba. The work has been based on field work and photointerpretation to determine the origin, amount of mobilized snow, and damage on the natural environment and human infrastructures. We have considerate the snow volume, height, geometry, impact pressures and speed as aapproximation to the transport capacity and damage potential of the Cardaño avalanche. The avalanche took place between February 9 and 13, when the snow height reached more than $2 \mathrm{~m}$, causing the snowpack instability. A dry flowing avalanche type was generated running down by slopes of $36.5^{\circ}$ from a altitude of $\sim 1900-2070 \mathrm{~m}$ reaching the bottom of the valley at 1415 m. $51000 \mathrm{~m}^{3}$ were moved to a estimated speed between 20.5 and $29.8 \mathrm{~m} \mathrm{~s}^{-1}$. The impact pressure of the snow on the valley bottom was between 10.2 and $20.8 \mathrm{~kg} / \mathrm{m}^{2}$. The avalanche caused several damage in the valley. The most important was the wreckage of the Club Espigüete Hostel, but also were damaged the rural path, the church roof, power cable and pole, and walls. The magnitude of avalanches advised to make detailed studies on avalanche risk and manage land for risk mitigation receptive to the traditional and scientific knowledge of snow and avalanches. KEY WORDS: snow avalanches, risks, geomorphology, Cantabrian Mountains.

\section{INTRODUCCIÓN}

La nieve es uno de los elementos más importantes del medio natural de la Montaña Cantábrica, y en particular en su porción central, donde se concentran los macizos más altos. Los elevados índices de innivación y las condiciones térmicas moderadas durante el invierno implican una larga temporada (invierno y primavera) donde la nieve constituye un aspecto fundamental del funcionamiento de los ecosistemas cantábricos, pero sobre todo es determinante para la dinámica geomorfológica e hidrológica. La nieve es el elemento clave para los regímenes fluviales, para la circulación hídrica superficial, para los regímenes térmicos de suelos y en general para todos los procesos geomorfológicos en laderas y fondos de valle. La presencia del manto nival implica la protección del suelo frente a la helada en los periodos clave del año, la saturación de los suelos durante el periodo de fusión nival, el lento trabajo de lavado superficial y subsuperficial durante más de seis meses al año, y en particular la acción de los desplazamientos del manto nival, los aludes.

Si en zonas de montaña con una elevada densidad de población y uso turístico invernal es vital la comprensión de la dinámica de aludes y la evaluación de riesgos de aludes, en las zonas de baja densidad, pero con incremento del uso turístico y excursionista invernal, también es necesario conocer con detalle el comportamiento del manto nival, su importancia geoecológica y la dinámica de los aludes. En este sentido, la bibliografía sobre física de la nieve y aludes es muy extensa, principalmente con el objetivo de predecir la formación y el desencadenamiento de aludes y existen numerosos estudios geomorfológicos focalizados en los aludes como sistemas de transferencia de derrubios capaces de generar formas de modelado.Sin embargo, en la Cordillera 
Cantábrica, aunque existen estudios orientados tanto al riesgo como a su efectividad geomorfológica, estos son escasos y recientes.

Estudios sobre las consecuencias de los aludes en la Península Ibérica (CRUZ, 1987; RODÉS, 1999, 2012; LÓPEZ MARTíNEZ et al. 2000) se han centrado en los daños a esquiadores, pero con el incremento de la frecuentación el riesgo está ascendiendo incluso en los macizos menos frecuentados, con especial incidencia en la Cordillera Cantábrica. En los Pirineos existen numerosos estudios aplicados y teóricos, sin embargo en la Cordillera Cantábrica los trabajos son más recientes, dedicados principalmente a los efectos geomorfológicos de la nieve (CASTAÑón, 1984; PUENTE, 2006; GONZÁLEZ TRUEBA, 2007; CARRERA y VALCÁRCEL, 2010; GONZÁLEZ TRUEBA y SERRANO, 2010; SANTOS et al. 2010; PELliTERO y SERRANO, 2012; GARCÍA et al. 2014; HERNÁNDEZ HOLGADO, 2014) o a la detección del riesgo de aludes, centrado en regiones (Wozniak y Marquínez, 2004) o ámbitos locales como los Picos de Europa (VADA et al. 2012; 2013) o Alto Campoo (SERRANO y GóMEZ LENDE, 2015). Todos estos trabajos han mostrado, por un lado, la importancia de la nieve como agente geoecológico en la Cordillera Cantábrica, y en particular desde un punto de vista geomorfológico, y en segundo lugar que se trata de un medio muy inestable con procesos peligrosos, como son los aludes, que es necesario conocer. Aunque estas montañas no son, salvo excepciones como los Picos de Europa, ni muy altas ni muy escarpadas, reciben una fuerte innivación derivada de su carácter atlántico que hace del manto nival un elemento primordial de su naturaleza. El interés creciente por el estudio de la nieve se basa en su consideración como recurso, para la gestión de embalses (Programa ERHIN), hidrológico, turístico y en particular para conocer su efectividad geomorfológica e importancia en la transferencia de sedimentos en medios de montaña y como riesgo natural.

En los últimos cinco años en la porción central de la Montaña Cantábrica han fallecido por aludes 6 personas (uno en Campoo, Cantabria, dos en el Espigüete y dos en el Curavacas -ambos en la Montaña Palentina-, y uno en el Mampodre, León). En los últimos 25 años, sólo en Alto Campoo -Cantabria-, al menos 5 personas han tenido que ser rescatadas de aludes. Por ello, conocer la dinámica del manto nival y el riesgo de aludes es una necesidad vital para sociedades avanzadas con elevada frecuentación de las montañas. El riesgo de aludes atañe a dos aspectos, por una parte la elaboración de partes de riesgo de aludes, que nos informan del estado de la nieve en un momento concreto, con un componente temporal, actualmente implementados por AEMET e iniciativas particulares (MeteoCampoo, Proyecto ENACC). Pero la predicción temporal debe completarse con la información espacial del riesgo de aludes, mediante el inventario y cartografía, que implica en particular a la ordenación 
del territorio, como consta, por ejemplo, en el Reglamento de Urbanismo de Castilla y León.

Pero a pesar de las aportaciones recientes y el interés de la nieve y de las montañas como recurso turístico, los aludes como riesgo no son objeto de atención en Castilla y León. Aunque la Ley de Urbanismo de Castilla y León (BOCYL, 5/1999) incluye referencias a los riesgos naturales, sin especificar sobre aludes, el Reglamento de Urbanismo de Castilla y León (BOCyL de 17 de julio de 2009, modificado el 17 de agosto de 2009) menciona de modo explícito los aludes como limitaciones en el art. 18.1 («Los propietarios de bienes inmuebles deben respetar las limitaciones impuestas en áreas amenazadas por riesgos naturales $[\ldots / \ldots]$, tales como $[\ldots / \ldots]$ alud, $[\ldots / \ldots])$. En dichas áreas la ley expone que «no debe permitirse ninguna construcción, instalación o uso del suelo incompatible con tales riesgos». En el art. 30, sobre suelo rústico, se señala alos terrenos amenazados por aludes bajo un criterio deprevención de riesgos y dotado de la categoría de suelo rústico con protección especial. En el art. 52se cita la prevención activa de riesgo, incluidos los aludes, y en el art111.3 se alude de modo genérico a la inclusión de un mapa de riesgos naturales en los planes de ordenación. A día de hoy no existen planessobre cartografía o prevención de aludes a pesar de que paulatinamente se incrementa el riesgo, derivado principalmente de una mayor frecuentación de la montaña invernal. Durante la última década se ha incrementado la frecuentación de la montaña invernal con motivo de la expansión de las prácticas del esquí de montaña y del excursionismo con raquetas; y la red de comunicaciones ha favorecido el incremento de la frecuentación de las mismas en periodos de riesgo, tanto hacia la montaña y su interior, como desde ella hacia el somontano.

En la Montaña Cantábrica las nevadas invernales asociadas a temporales del $\mathrm{N}$ y NW generan importantes espesores de nieve, que superan los 2 metros, $\mathrm{y}$ una elevada inestabilidad del manto nival. Esta inestabilidad no se limita a las zonas de la alta montaña, las nevadas más frecuentes, con periodos bianuales, generan aludes de tamaños 3 y 4 (según el Canadian Snow Avalanche Size, en adelante CSAS; y la European Destructive Size Scale, en adelante EDSS, MCClung y SHAERER, 1980; StATHAM y MCMAHON, 2004; CAA, 2007; MONER et al. 2013), capaces de dañar edificios, infraestructuras, bosques y personas. Los estudios de los efectos de los aludes asociados a periodos de fuerte innivación tanto históricos, por ejemplo los de 1888, 1918, 1957/58 o 1978, que afectaron a todo el conjunto de la Cordillera Cantábrica por temporales del N y NW e involucraron a toda la Península Ibérica, como sobre aludes recientes, realizados desde AEMET, las universidades de Oviedo, León o Cantabria, muestran la importancia de estos sucesos y el interés creciente por 
su conocimiento. Este interés se traduce en dos hechos, por un lado la presencia y distribución de los aludes para conocer su efectividad geomorfológica e importancia en la transferencia de sedimentos en medios de montaña, y por otro generar herramientas para conocer los riesgos asociados a los aludes e implementar medidas de mitigación del riesgo y de gestión del territorio. Ambas cuestiones son poco conocidas en laCordillera Cantábrica y son objeto de estudio en la última década.

Estudios recientes realizados por el Grupo de Investigación PANGEA de la Universidad de Valladolid han permitido caracterizar los aludes de alto Campoo, grupo de montañas situado a $30 \mathrm{~km}$ al oeste del Alto Carrión, con altitudes en torno a los $2100 \mathrm{~m}$ y un relieve menos enérgico. En términos generales los aludes de Campoo son de reducido tamaño, si bien existen reiteradossucesos de grandes aludes en el Picos Cordel $(2.081 \mathrm{~m})$ y dominan los aludes de placa, los desprendimientos de nieve húmeda y aludes de cornisa. Responden a unas distribuciones precisas, a sotavento y con componentes sur y este, y en alto porcentaje son originados por el tránsito de esquiadores o excursionistas. La elaboración de un mapa de zonas de aludes es de interés para los estudios geomorfológicos y aplicados, y un mapa de riesgo de aludes, aplicado a la información espacial del riesgo, para la gestión de los flujos y frecuentación de la montaña.

\section{LA ZONA DE ESTUDIO}

El valle de Cardaño se sitúa en la porción central de la Cordillera Cantábrica (FIGURA 1), entre los $4^{\circ} 01^{\prime} 26^{\prime \prime} \mathrm{W}$ y los $4^{\circ} 42^{\prime} 52^{\prime \prime} \mathrm{W}$ de longitud y los $43^{\circ} 48^{\prime} 4^{\prime \prime} \mathrm{N}$ y $42^{\circ} 54^{\prime} 50^{\prime \prime} \mathrm{N}$ de latitud. Constituye un valle de dirección dominante norte-sur, drenado por el río Cardaño, afluente de Carrión, vertiente al Duero, enclavado entre las cumbres más elevadas de la Cordillera (macizo de Peña Prieta, $2.539 \mathrm{~m}$, inmediatamente al norte). Los valles que drenan al río Cardaño forman elevados cordales (Espigüete, $2.451 \mathrm{~m}$, Murcia, $2.351 \mathrm{~m}, \mathrm{Pe}-$ ñas Matas, $2.281 \mathrm{~m}$, al oeste; Lomas, $2.457 \mathrm{~m}$, Alto de Fuentes Carrionas, $2.421 \mathrm{~m}$, al norte; y Alto del Ves, $2.126 \mathrm{~m}$, o Alto Prieto, $2.032 \mathrm{~m}$, al este) que articulan una red de ocho valles afluentes encajados entre cordales que superan los $2000 \mathrm{~m}$ de altitud.

El valle forma parte del Macizo Asturiano y se estructura en unidades cabalgantes en escamas y mantos que configuran sucesivos alineamientos de direcciones dominantes E-W, derivados del conjunto de pliegues cabalgantes de dirección general WNW-ESE desde Peña Prieta hasta el cabalgamiento calizo del Espigüete. Se caracterizan por la intensa tectonización y la diversidad litológica, alternando calizas, areniscas, lutitas, conglomerados y pizarras paleozoicas en bandas de dirección paralela (ALONSO, 1987). 
Figura 1. Localización del valle de Cardaño

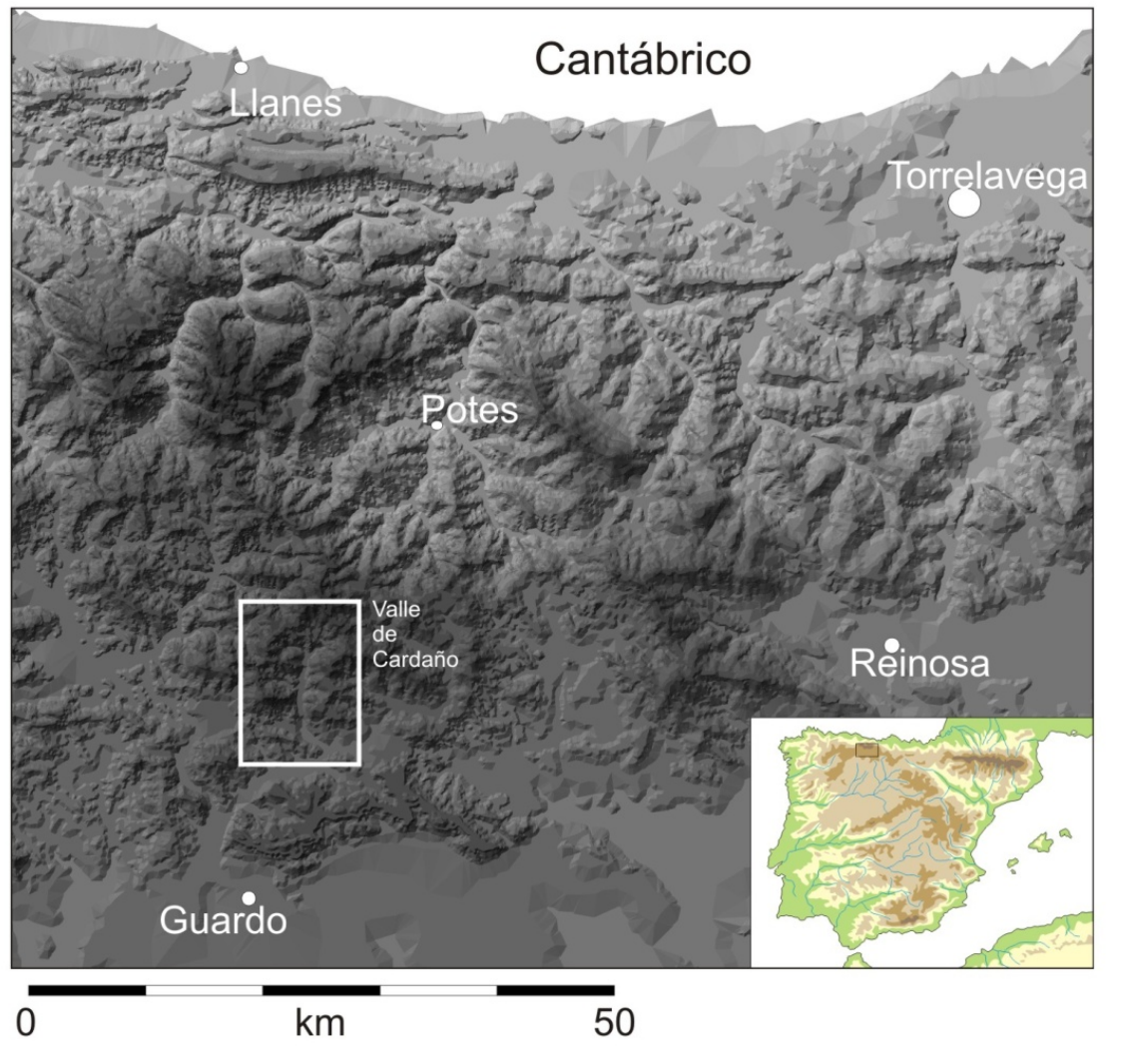

El valle de Cardaño es una artesa glaciar modelada por los glaciares pleistocenos formando circos, valles en artesa y complejos morrénicos laterales y frontales, como el de Cardaño de Abajo, 6kms al sur de Cardaño de Arriba (Pellitero, 2009; 2013; 2014). Sobre el valle principal, artesa glaciar de paredes verticales y de fuerte pendiente y fondo plano derivado del relleno postglaciar, se modelaron valles y circos colgados como el circo glaciar de El Castillo-Cerro de El Sillar, procedencia del alud que nos ocupa.

El volumen y altitud de esta porción de la Montaña Palentina propician una intensa innivación y un extenso manto nival que se emplaza entre diciembre y enero y se mantiene hasta mayo junio, en función de la altitud. El periodo de nevadas más intensas coincide con la llegada frentes del $\mathrm{N}$ y NW, prioritariamente de finales de enero a marzo, y coincide con el periodo de precipitaciones más importante. En la zona se registran 26 días de nieve anuales en Cervera de Pisuerga (996 m), 55 días en Piedrasluengas (1336 m) y más de 70 
en los valles internos, como la Pernía o Cardaño. A estos periodos de intensas nevadas, asociados a los temporales de invierno, se contraponen situaciones de tiempo sur o suroeste, donde acceden masas de aire templadas y húmedas, que propician lluvias de intensidad variable y periodos de fusión rápida por el incremento de la temperatura y del viento. Este hecho implica que en la zona el manto nival se presenta a menudo húmedo, y con unaelevada variabilidad interanual, como sucedió en los años 2004 y 2005 en los que el segundo dobló en innivación al anterior. Grandes periodos de nevadas $(2005,2013)$ se alternan con periodos de poca innivación $(2004,2012)$. Además, la amplia variabilidad estacional implica una elevada inestabilidad del manto nival todos los años, lo que al tiempo propicia su eficacia como agente geomorfológico (Pellitero, 2012; Pellitero y Serrano, 2012; Serrano y Gómez LENDE, 2015).

El valle de Cardaño se encuentra en el «Parque Natural de Fuentes Carrionas y Fuente Cobre-Montaña Palentina», declarado por ley de la Comunidad Autónoma de Castilla y León en el año 2000 (BOCYL, 4/2000 de 27 de junio). El valle se emplaza en unaUnidad de Especial Fragilidad, y en la Zona de Uso Limitado B. Este es un hecho importante por cuanto el Parque Natural tiene responsabilidad en la gestión del territorio y en la consideración de zonas de riesgos, así como en la promoción, limitación y gestión de flujos de visitantes. La Ley 4/2011, de 29 de marzo, «Directrices de Ordenación de Ámbito Subregional de la Montaña Cantábrica Central en Castilla y León», incluye a la Montaña Palentina como una Unidad de Gestión de Paisaje y el ENP Montaña Palentina como un recurso turístico. El art. 65 propone la zona de Cardaño como «eje estratégico» y en los art. 72 y 73 se establece de modo explícito la potenciación de las actividades de montaña y el aprovechamiento del «recurso nieve», proponiendo desestacionalizar el turismo y promover el excursionismo con raquetas por la montaña y alta montaña (literalmente «raquetas de nieve, circuitos de esquí de fondo, rutas de travesía»), con la creación de «puntos activos vinculados a la nieve». Pero la nieve, además de un recurso, constituye un riesgo derivado de su dinamismo, inestabilidad y condición dinámica, lo que obliga a conocer, caracterizar y zonificar espacialmente aquellas áreas en las que se pretenda desarrollar estas actividades. El uso de la montaña invernal para actividades de ocio (alpinismo, raquetas de esquí, esquí de montaña, excursionismo) conlleva un riesgo, y su promoción debe ser acompañada de planes de prevención e información, actualmente ausentes en la Montaña Palentina. Debe existir una clara diferenciación entre el riesgo individual, afrontado por el montañero (alpinista, escalador, esquiador de montaña) bajo su libre toma de decisiones en actividades de riesgo personales, y la promoción de actividades colectivas y desarrollo territorial que implican actividades de riesgo asociadas a riesgos naturales. En este sentido, las instituciones deben 
dotar de la información y el conocimiento necesarios para establecer planes de mitigación y prevención del riesgo, ya previstos en la ley pero inexistentes en la realidad. Hasta ahora sólo existen algunas aproximaciones a la peligrosidad de los aludes en la zona de estudio desde los ambientes montañeros (Foro Picos) y académicos (PELlitero, 2013), como iniciativas particulares y a menudo desdeñadas por las autoridades y gestores.

De igual modo, si en el art. 72 se propone la creación de refugios de montaña, su construcción debe implicar el estudio de la nieve en la alta montaña, los riesgos asociados a los procesos naturales y las condiciones ambientales de los emplazamientos, hecho que hasta ahora no se ha tenido en cuenta, valga de ejemplo la reconstrucción del refugio de montaña de Cardaño tras su destrucción por el alud en el año 2015.

\section{METODOLOGÍA}

El método de trabajo se ha basado en el trabajo de campo y la fotointerpretación para la reconstrucción del área afectada por el alud, determinar su procedencia, la cantidad de nieve movilizada y los daños causados en el medio natural y sobre las infraestructuras humanas (FURDADA, 1996; MCCLUNG y SCHAERER, 1996; JULIÁN et al. 2000; PALOMO, 2007; FERNÁNDEZ CAÑADAS, 2014; FERNÁNDEZ SANTOS et al. 2015). Se ha realizado un registro e inventario de daños, tipo, localización y procedencia de la nieve. En el planteamiento de la investigación se propuso la elaboración de encuestas, sin embargo, la despoblación del caseríoen invierno, y durante el periodo de aludes estudiado en particular, y la escasa presencia de casas habitadas en la primavera, impidió la realización de las mismas. Se detectaron sólo dos habitantes ocasionales (residencia secundaria) que por ser de fuera y desconocer en detalle la naturaleza y las condiciones invernales, no fueron de utilidad.

Se ha realizado un análisis de la situación meteorológica previa y durante el alud en la zona de estudio. Se han utilizado las imágenes de satélite infrarrojo de EUMESAT, modificadas e interpoladas por Meteociel.fr, y datos de temperaturas y precipitaciones de AEMET, así como las observaciones sobre el espesor del manto nival a $1.650 \mathrm{~m}$ y $2.100 \mathrm{~m}$ en Alto Campoo y el telenivómetro de Valdecebollas (CHE). Se han podido establecer las condiciones sinópticas, flujos y vientos dominantes, tipos de precipitaciones, la cantidad de nieve caída en las semanas previas y para diferentes altitudes, así como la intensidad de las precipitaciones.

Para el análisis de las zonas y canales de aludes y su posible reactivación durante el evento de 2015, se ha utilizado la cartografía geomorfológica a es- 
cala $1 / 10.000$, donde existe un inventario de canales de aludes y zonas de llegada (Pellitero, 2013). Esta información se ha completado, en el ámbito afectado, con la reconstrucción de la zona ocupada por el alud, así como con un mapa de pendientes y de insolación máxima y mínima, elaborados mediante herramientas SIG. La combinación de estas cartografías permite estimar la sensibilidad de las laderas para la génesis y desplazamiento de los aludes.

Finalmente, a partir de los datos de campo se ha considerado el volumen, peso de la nieve, geometría, presión de impacto estimada y velocidad estimada en las porciones media y final (GRAY y MALE, 1981; MCCLUNG y LIED, 1987). Estas estimaciones presentan problemas de precisión derivadas de la imposibilidad de conocer algunas variables, tales como el estado previo de la capa superficial (densidad, temperatura), la densidad de la nieve desplazadapor el alud, la geometría de la ladera (modificada en invierno en función del manto nival), pero permiten una aproximación a la capacidad de transporte y al potencial de daños del alud de Cardaño.

\section{CONDICIONES AMBIENTALES EN FEBRERO DE 2015}

Durante el mes de febrero se generaron grandes nevadas, en 15 días las precipitaciones en forma de nieve alcanzaron $\operatorname{los} 250 \mathrm{~cm}$ de espesor, formando un potente manto nival. Durante el mes de enero las precipitaciones en forma de nieve habían acumulado un manto a $1.650 \mathrm{~m}$ de $60 \mathrm{~cm}$ y a $2.115 \mathrm{de} 90 \mathrm{~cm}$ de espesor, alcanzado en 10 días de precipitaciones en forma de nieve. Tras cinco días de buen tiempo entre el 24 y el 28 de enero constituía ya un manto estable y evolucionado.

Entre el 1 y el 6 de febrero un frente frío del NW trae consigo un fuerte temporal que barre la Cordillera Cantábrica de NW a SE. Las imágenes de satélite infrarrojo de EUMESAT muestran el barrido frontal, y los máximos de precipitación nival, en torno a los macizos más elevados, Picos de Europa y la Montaña Palentina, si bien los máximos se dan en la montaña oriental de Cantabria, en macizos más bajos pero próximos al mar, donde superan los 3 $\mathrm{m}$ de espesor. En el sector de Cardaño señalan precipitaciones de $100-150 \mathrm{~cm}$ de nieve. En la primera semana de febrero el telenivómetro de Valdecebollas, a $1700 \mathrm{~m}$, señala una acumulación de $188 \mathrm{~cm}$ de nieve, que en las laderas y ventisqueros, por la acción del viento, llegan a superar más de $2 \mathrm{~m}$ de espesor. Los vientos generaron cornisas de nieve y placas de viento en orientaciones E, SE y NE.

Las nevadas del 31 de enero y 1 de febrero continúan hasta el 7 de febrero (CUADRO 1), con una acumulación de $120 \mathrm{~cm}$ de nieve fresca sobre el manto 
nival evolucionado a $1.650 \mathrm{~m}, 140 \mathrm{~cm}$ de nieve fresca a $2.115 \mathrm{~m}, \mathrm{y} 173 \mathrm{~cm}$ en Valdecebollas, a $1.700 \mathrm{~m}$. El telenivómetro de Valdecebollas indica un espesor de nieve a $1.700 \mathrm{~m}$, en la Montaña Palentina, de $333 \mathrm{~cm}$, y los espesores alcanzados a $1.650 \mathrm{~m}$ y $2.115 \mathrm{~m}$ son de $180 \mathrm{~cm}$ y $230 \mathrm{~cm}$ respectivamente. Son cifras de espesor de nieve muy altas para la Montaña Cantábrica, y conllevaron el aislamiento de numerosos pueblos de la Montaña Palentina durante cerca de una semana y el corte de carreteras, como la Autovía de la Meseta, que permaneció cerrada durante tres días. El día 9 de febrero hay un manto nival en torno a $2.000 \mathrm{~m}$ compuesto de un estrato de $90 \mathrm{~cm}$ de nieve evolucionada y uno superior de $140 \mathrm{~cm}$ de nieve fresca, en polvo, reposando sobre una capa parcialmente helada o saturada en agua durante los días 24-28 de enero, cuando hace buen tiempo y llueve.

Cuadro 1. El espesor de la nieve en la Montaña Cantábrica central entre el 29 de enero y el 8 de febrero de 2015

\begin{tabular}{|c|c|c|c|c|c|}
\hline \multirow{2}{*}{ Periodo } & \multirow{2}{*}{$\begin{array}{l}\text { Altitud } \\
(\mathrm{m})\end{array}$} & \multicolumn{3}{|c|}{ Espesor de nieve $\mathrm{cm}$} & \multirow{2}{*}{ Observaciones } \\
\hline & & (a) & (b) & (C) & \\
\hline \multirow{3}{*}{$29 / 01$} & 1.650 & -- & -- & 60 & \multirow{3}{*}{$\begin{array}{l}\text { En enero se acumulan } 35 \\
\mathrm{~cm} \text { a } 1600 \text { y } 50 \text { a } 2115 \text {. Fu- } \\
\text { sión de } 20 \mathrm{~cm} \text { de espesor } \\
\text { entre el } 23 \text { y el } 29\end{array}$} \\
\hline & 1.700 & -- & -- & 160 & \\
\hline & 2.115 & -- & -- & 90 & \\
\hline \multirow{3}{*}{$31 / 01$ a $02 / 02$} & 1.650 & 15 & 15 & 75 & \multirow{3}{*}{$\begin{array}{l}\text { Nevadas en altitud, con in- } \\
\text { cremento del espesor del } \\
\text { manto nival en altura. }\end{array}$} \\
\hline & 1.700 & 59 & 59 & 219 & \\
\hline & 2.115 & 100 & 100 & 190 & \\
\hline \multirow{3}{*}{$03 / 02$ a $06 / 02$} & 1.650 & 95 & 110 & 170 & \multirow{3}{*}{$\begin{array}{l}\text { Nevadas en cotas bajas y } \\
\text { acumulación moderada en } \\
\text { altitud. Carreteras corta- } \\
\text { das. }\end{array}$} \\
\hline & 1.700 & 31 & 90 & 350 & \\
\hline & 2.115 & 30 & 130 & 220 & \\
\hline \multirow{3}{*}{$06 / 02$ a $08 / 02$} & 1.650 & 10 & 120 & 180 & \multirow{3}{*}{$\begin{array}{l}\text { Nevadas moderadas a to- } \\
\text { das las altitudes }\end{array}$} \\
\hline & 1.700 & 17 & 107 & 267 & \\
\hline & 2.115 & 10 & 140 & 230 & \\
\hline \multirow{3}{*}{$\begin{array}{l}\text { Total: } \\
31 / 01 \text { a } 08 / 02\end{array}$} & 1.650 & 120 & 120 & 180 & \multirow{3}{*}{$\begin{array}{l}\text { En } 9 \text { días se acumula un } \\
\text { espesor de nieve de } 1,4 \text { a } \\
1,7 \text { m en torno a } 2000 \text { me- } \\
\text { tros. }\end{array}$} \\
\hline & 1.700 & 107 & 107 & 267 & \\
\hline & 2.115 & 140 & 140 & 230 & \\
\hline
\end{tabular}

(a), Absoluto; (b), Acumulado; (c), Total

FUENTE: Datos, CANTUR y CHE. Tabla, elaboración propia

El 9 de febrero se instala un anticiclón en la Península Ibérica con tiempo estable, que conlleva la ausencia de nubosidad, fuerte radiación diurna y un ascenso de las temperaturas que perdura hasta el 15 de febrero. La estructura del manto nival reciente, formado por un estrato superior muy inestable repo- 
sando sobreel antiguo (FIGURA 2), propicia la existencia de un nivel de ruptura, que de modo generalizado se romperá en distintas laderas del valle, todas ellas en orientaciones SE, E y NE.

Figura 2. Nieve caída en la temporada 2014/2015 y número de días de nieve (arriba), y estructura del manto nival entre el 2 y el 9 de febrero de 2015 (abajo)

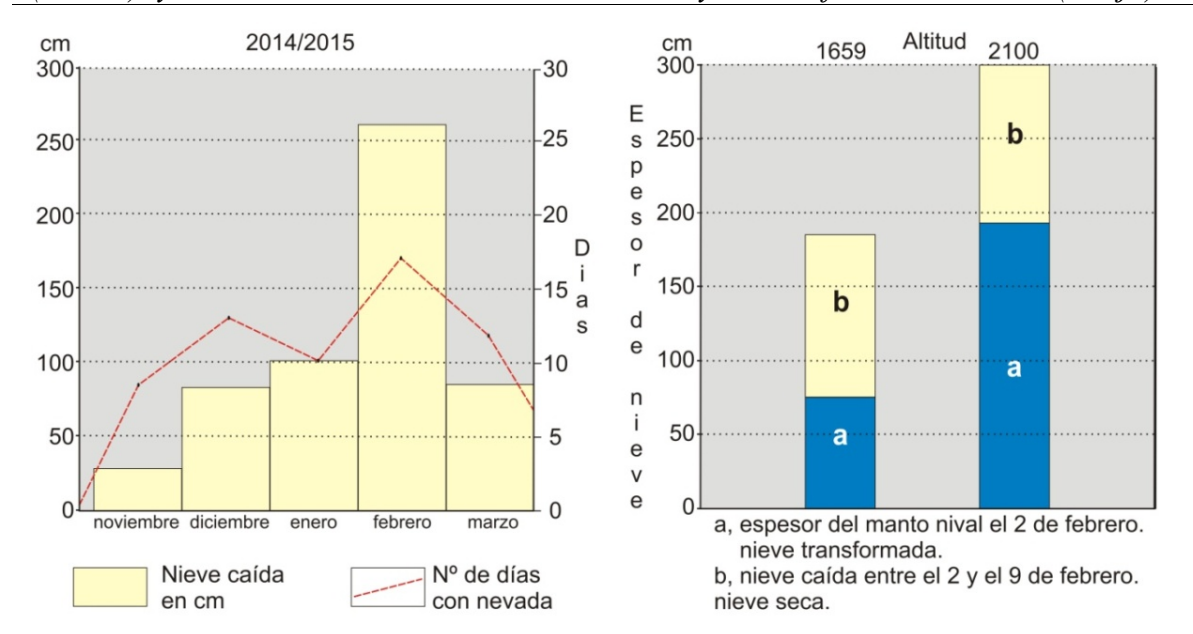

FUENTE: Datos, CANTUR y CHE. Gráfico, elaboración propia

\section{LOS ALUDES DE FEBRERO DE 2015 EN ALTO CARRIÓN}

En febrero de 2015 se produjeron en Alto Carrión tres importantes aludes que causaron destrozos en la carretera de acceso a Cardaño de Arriba, en el pueblo y en la Vega de Valcabe. Aunque se desconoce la fecha, todos ellos tuvieron lugar entre el 9 y el 13 de febrero, durante el periodo anticiclónico posterior al temporal del NW.

\section{V.1. Los aludes de Valcabe y Carretera de Cardaño.}

En la zona de estudio se han registrado 5 sectores con sucesivos aludes de gran envergadura (FIGURA 3) entre los que destaca el macizo de Espigüete, donde los aludes surcan con frecuencia las vertientes N, S y E (Pellitero, 2013). Pero si en el macizo los aludes sólo interfieren con algunas pistas y, primordialmente, con las actividades alpinísticas y montañeras, es en la vertiente oriental donde los aludes caen sobre el valle de Cardaño y generan daños en la carretera (FIGURA 4). En el año 2015cae un alud sobre la carretera (CUADRO 2) generado en la ladera oriental, amplio sector dominado por los aludes en todas las grandes nevadas, a favor de la construcción de grandes cornisas y placas de viento que se transforma rápidamente en orientaciones este. Los aludes se encauzan por los canales inferiores, sin alcanzar la mayoría 
de las veces el fondo de valle y los abedulares del pie de las canales, como sí ocurrió sin embargo en el mes de febrero de 2015. La carretera fue dañada parcialmente y sepultada por la nieve, los ramajes y troncos, junto a arenas y gravas transportados por la nieve.

Figura 3. Localización de las zonas con aludes. 1, carretera de acceso a Cardaño de Arriba. 2, Cardaño de Arriba y circo de El Hoyo. 3, Valcabe.

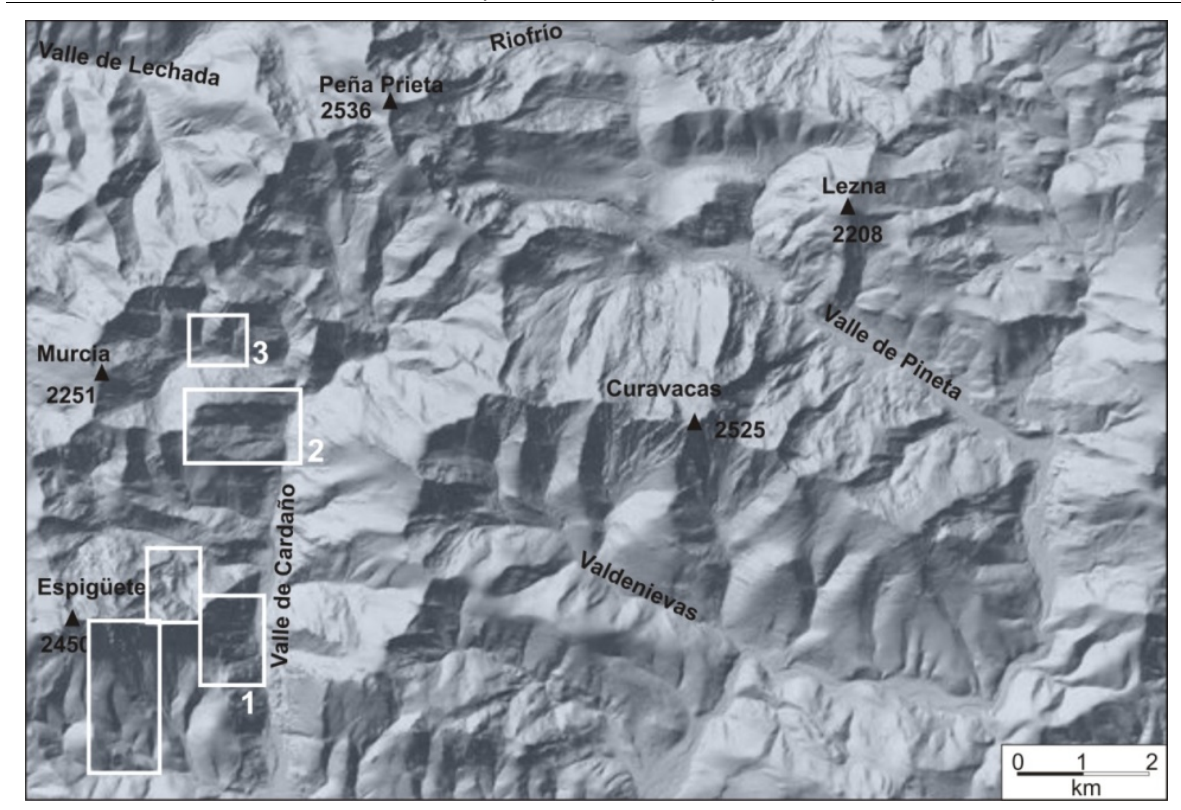

FUENTE: Elaboración propia

En el valle de Valcabe, al norte de Cardaño de Arriba, en la ladera sur de las Peñas Matas (2.281 m) se desencadenó un alud (CUADRO 2) que dañó la cabaña de pastores, trasladando su techumbre hasta el fondo del valle. Se trata de un alud de reducidas dimensiones generado en una fuerte pendiente (30$40^{\circ}$ ) por la rápida transformación de la nieve sobreacumulada en una orientación sur. La corta pero fuerte pendiente, por ser parte de la ladera de la artesa glaciar que confluye en la de Cardaño, y la orientación meridional propician la alta peligrosidad no sólo de la ladera, sino de toda la vertiente norte del valle, orientado de $\mathrm{E}$ a $\mathrm{W}$, con pendientes muy fuertes orientadas al $\mathrm{S}$. La inexistente ocupación invernal reduce el riesgo, pero en la actualidad se da unincremento del mismo en la ladera y en el fondo de valle debido a la frecuentación por situarse en la ruta normal de ascensión al Pico Murcia, un clásico del esquí de montaña y del montañismo invernal, promovido además 
desde las Directrices de Ordenación de Ámbito Subregional de la Montaña Cantábrica Central en Castilla y León.

Cuadro 2. Características de los aludes de la Carretrea de Cardaño y Valcabe

\begin{tabular}{|c|c|c|}
\hline Nombre & $C^{a}$ de Cardaño & Valcabe \\
\hline Tipo de alud & Alud de placa & Alud de placa \\
\hline Tipo de nieve & Seca & Seca \\
\hline Origen & $\begin{array}{l}\text { Cornisa y placa de viento. } \\
\text { Natural. }\end{array}$ & -- \\
\hline Orientación & $\mathrm{E}$ & $\mathrm{SE}$ \\
\hline Altitud Raíz & $\sim 1.860-1.950$ & 2.030 \\
\hline m s.n.m. $\quad$ Frente & 1.340 & 1.650 \\
\hline Longitud (m) & $\sim 800$ & 540 \\
\hline Desnivelm & 600 & 380 \\
\hline Pendiente & $38^{\circ}$ & $30^{\circ}$ \\
\hline Porción media & $33^{\circ}$ & $40^{\circ}$ \\
\hline Final & $8,6^{\circ}$ & $7^{\circ}$ \\
\hline $\begin{array}{l}\text { Tamaño del alud } \\
\text { (escala CSAS) }\end{array}$ & 3 & 3 \\
\hline Daños & $\begin{array}{l}\text { - Carretera PP2102 } \\
\text { - Abedular en la canal }\end{array}$ & $\begin{array}{l}\text { - Cabaña de pasto- } \\
\text { res, techumbre. }\end{array}$ \\
\hline
\end{tabular}

FUENTE: Elaboración propia

Los aludes inventariados tienen su zona de arranque en laderas con pendientes $>30^{\circ}$ y en cualquier orientación (FIGURA 5), si bien dominan los orientados al E (47\%). Se asocian a muy variadas recepciones de radiación, pero siempre a fuertes pendientes, $\mathrm{y}$ se puede apuntar como hipótesis para su desencadenamiento, la formación de cornisas generadas por vientos de componente $\mathrm{W}$, NW y SW, junto a la rápida transformación de la nieve tras la temprana recepción de radiación solar. Estas son las variables que dominan en la génesis de aludes en la zona estudiada. Los aludes con componente N (28\%) y S (25\%) están igual representados, los primeros asociados a la baja radiación invernal y los segundos a lo contrario, la elevada radiación incidente sobre el manto nival.

De este hecho puede deducirse que existen aludes de distinto tipo, nieve seca frente a nieve húmeda, y época, aludes de invierno y primavera. Este hecho se ha constatado en la ladera $\mathrm{S}$ del Espigüete, donde los aludes de nieve húmeda alcanzan cotas muy bajas $(1.350 \mathrm{~m})$ a final del invierno y principio de primavera, pero no en el resto del área estudiada. 
Figura 4. Alud de la carretera de Cardaño.

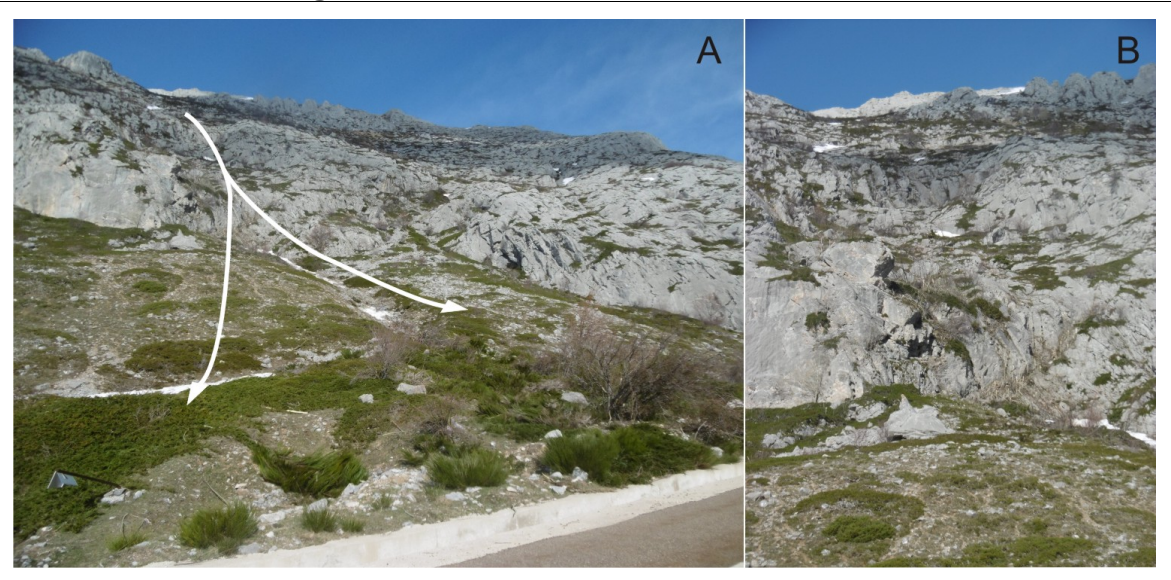

FUENTE: Elaboración propia

Figura 5. Mapa de pendientes e itinerarios de aludes (A) y mapa de radiación invernal (B) del sector Valcabe, CardañoEspigüete.

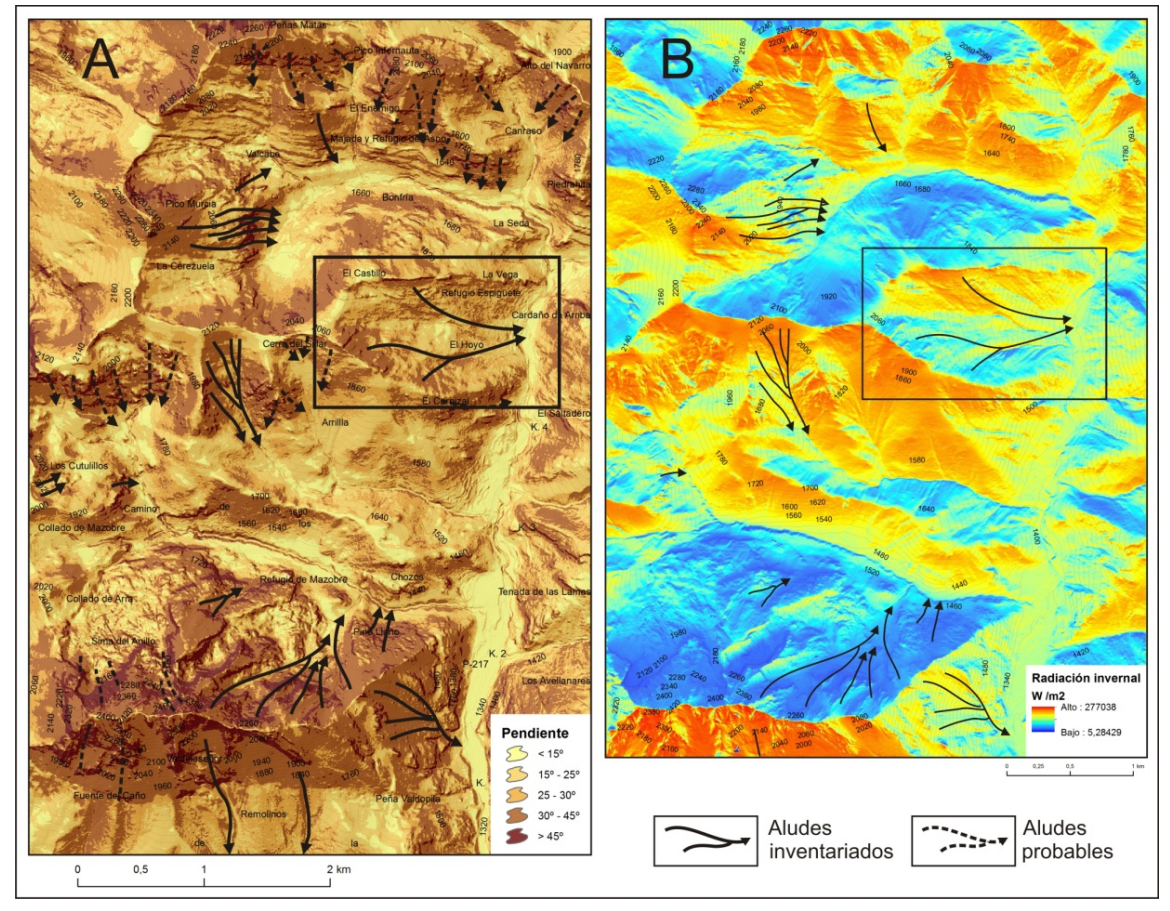

FUENTE: Elaboración propia 


\section{V.2. El alud de Cardaño de Arriba}

Cuadro 3. Características del alud de Cardaño de Arriba

\begin{tabular}{llc}
\hline Nombre & & Cardaño de Arriba \\
\hline Tipo de alud & & $\begin{array}{c}\text { Alud de flujo seco } \\
\text { Alud de placa }\end{array}$ \\
\hline Tipo de nieve & & Seca \\
\hline Origen & Raíz & Placa de viento, natural. \\
\cline { 2 - 3 } Altitud & Frente & $\sim 1900-2070$ \\
\hline Longitud & & 1415 \\
\hline Desnivel & Cabecera & $\sim 485-655 \mathrm{~m}$ \\
\hline Pendiente & Porción intermedia & $1100 \mathrm{~m}$ \\
\cline { 2 - 3 } & Final & $36,5^{\circ}$ \\
\hline Estimación de volumen desplazado & $24,5^{\circ}$ \\
\hline Tamaño del alud (escala CSAS) & $0^{\circ}$ \\
\hline Presión de impacto estimada & $51000 \mathrm{~m}^{3}$ \\
\hline Velocidad estimada (porción media final) & 4 \\
\hline Daños & - Destrucción total del refugio del Club Espigüete. \\
& - Deterioro del camino rural. & $20,5 / 29,8 \mathrm{~m} \mathrm{~s} \mathrm{~s}^{-1}$ \\
\hline & - Destrucción del arbolado de la vega. & \\
& - Daños en tejado de la iglesia parroquial, \\
& - Rotura del cable de la luz y daños en postes y registro. \\
& - Derrumbe del muro. & \\
\hline
\end{tabular}

FUENTE: Elaboración propia

Figura 6. Extensión del alud de Cardaño de Arriba y pendientes de salida y en la porción intermedia.

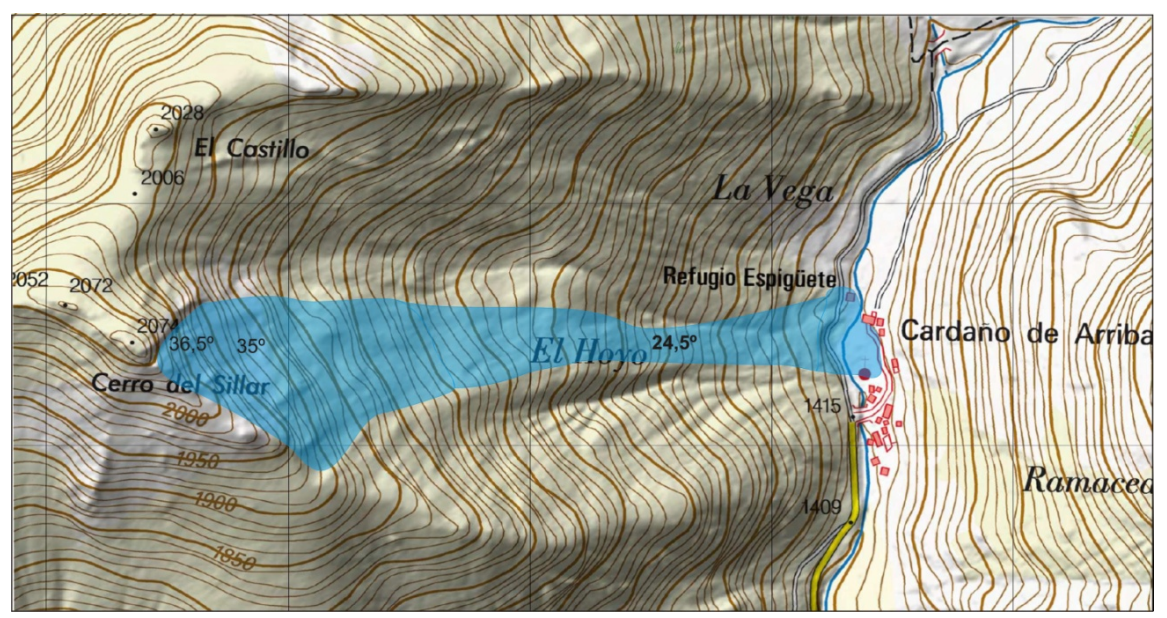

FUENTE: Elaboración propia 
El alud más importante en la zona de estudio (CUADRO 3) durante estos días alcanzó la población de Cardaño de Arriba procedente del valle denominado El Hoyo (FIGURA 6). El alud de Cardaño tuvo lugar entre el 9 y el 13 de febrero, encontrándose el pueblo deshabitado, por lo que no hay testigos directos.

Entre el 31 de enero y el 8 de febrero en torno a los $2.000 \mathrm{~m}$ de altitud se acumulan más $140 \mathrm{~cm}$ de nieve sobre el manto nival previo, y en las laderas y ventisqueros se acumulan mayores espesores, generándose cornisas de nieve y placas de viento en las laderas superiores, con espesores de nieve mayores de los $2 \mathrm{~m}$. Esta nieve reposaba sobre la capa de nieve preexistente, que a estas altitudes variaba entre 90 y $160 \mathrm{~cm}$ de espesor (según datos de Alto Campoo y Valdecebollas), creando las condiciones idóneas de inestabilidad del manto nival.

\section{V.2.a. Origen y dinámica del alud}

El origen del alud es natural, no inducido por la actividad humana, a favor de las condiciones meteorológicas y la estructura del manto tras la fuerte nevada. Su arranque se sitúa en las laderas de El Hoyo. El circo glaciar de El Hoyo es una cuenca de $122 \mathrm{Ha}$. limitada por los cordales de Cerro del Sillar $(2.074 \mathrm{~m})$ al sur y El Castillo $(2.028 \mathrm{~m})$ al norte, al pie de la cual se localiza el núcleo de Cardaño de Arriba, a 1415 m. Su cabecera se conforma en un circo glaciar con dos complejos morrénicos y un umbral de fuerte pendiente bajo el que se sitúa el pueblo. Las crestas orientadas al $\mathrm{N}$ y al $\mathrm{S}$ presentan pendientes superiores a $32^{\circ}$ y la ladera en el umbral sobre Cardaño de Arriba tiene $24,5^{\circ}$ de pendiente. Las primeras son claramente favorables para el desplazamiento de la nieve, mientras que la segunda no supera el umbral de $25^{\circ}$ pero favorece la movilización de masas procedentes de las porciones superiores.

El arrasamiento de los abedules situados en las vaguadas señala la procedencia de la masa de nieve del SW, si bien la zona de arranque exacta es difícil de predecir. En altura no existen huellas, pues la nieve movilizada se desplaza sobre el manto nival estable. Las laderas orientadas al NE del cerro del Sillar o las orientales de la porción del collado del Castillo podrían ser los ámbitos de arranque. La orientación E-W del valle de El Hoyo genera dos laderas con condiciones térmicas opuestas (FIGURA 7), si bien ambas presentan pendientes que superan los $30^{\circ}$. Al sur, coincide con las mayores pendientes y las más elevadas tasas de radiación invernal, lo que favorece la rápida transformación de la nieve. Por el contrario, al N, la mínima radiación recibida favorece el congelamiento de la superficie de la nieve y la formación de niveles de despegue. Las fuertes pendientes, con porciones de la ladera $>30^{\circ}$ en el umbral glaciar de El Hoyo, favorece el desplazamiento hacia el fondo de valle de las ma- 
Figura 7. Mapas del sector de El Hoyo-Cardaño de Arriba. Mapa de radiación invernal (arriba) y mapa de pendientes (abajo) con los sectores del alud; a, zona de comienzo; $b$, zona de recorrido; $y c$, zona de detención.
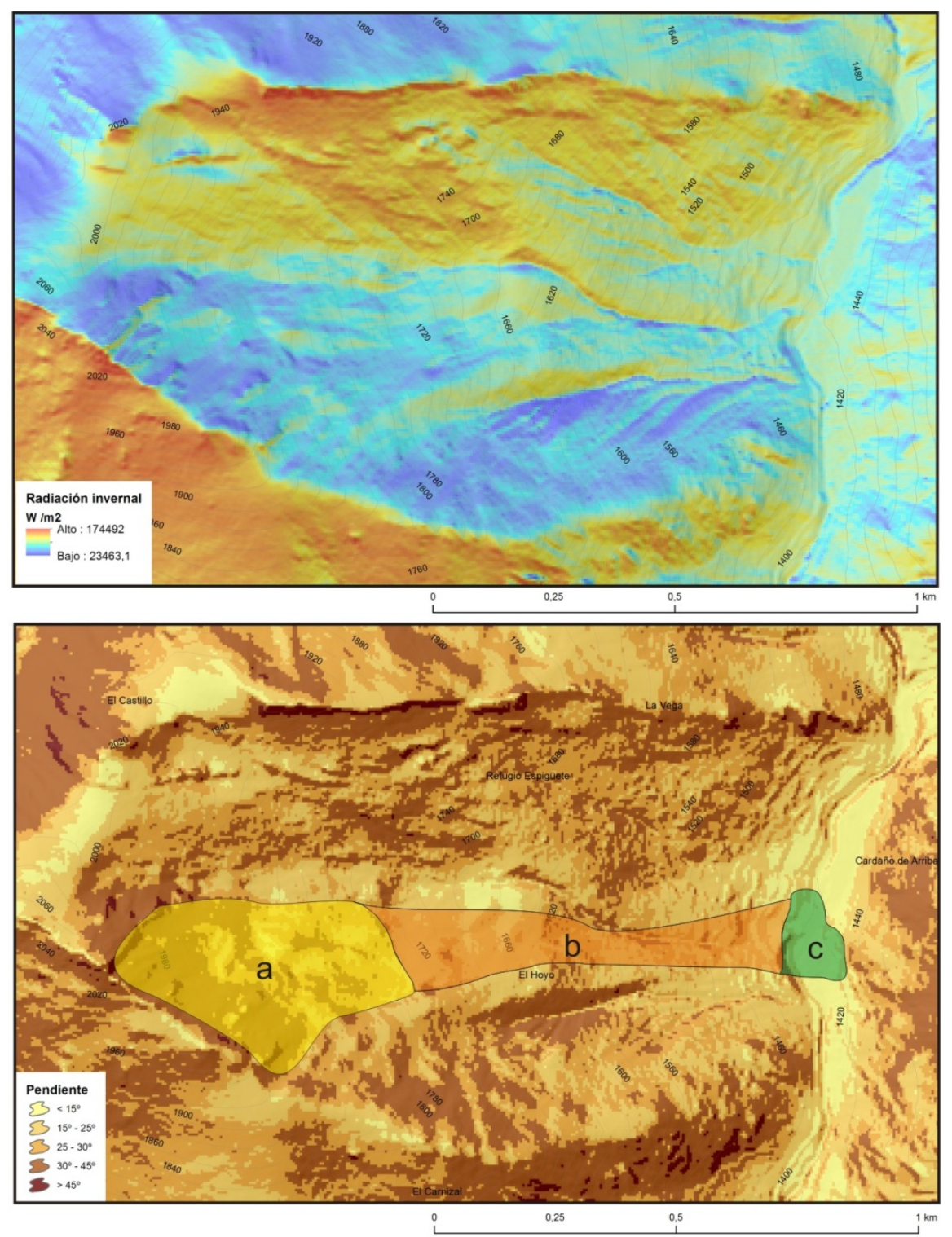

FUENTE: Elaboración propia

sas desplazadas. Su puesta en marcha podría estar a favor de una cornisa, cayendo sobre una placa de nieve en las pendientes mayores de $32^{\circ}$, o bien la 
pérdida local de cohesión y la ruptura directa sobre el cuerpo inferior de una porción del manto nival. La primera opción es la observada con mayor frecuencia en los aludes de mayor tamaño de la montaña palentina o Campoo.

La zona de arranque (a en FIGURA 7) no se ha podido establecer con precisión, pudiendo ser una amplia porción del circo, con pendientes de $30-40^{\circ}$, donde se dan las condiciones para que la masa de nieve se desplace hacia El Hoyo. Se trata, en cualquier caso, de un alud de placa de nieve seca que arranca en un sector donde se acumulan más de $2 \mathrm{~m}$ de nieve $(2,30$ a 2,60 m), de los cuales se pone en marcha la porción superior, entre 1,1 y $1,40 \mathrm{~m}$ de espesor de nieve, y se desliza hacia el fondo del valle como un flujo seco.

El alud desciende por el umbral, donde la pendiente, $>25^{\circ}$ al inicio y $>15^{\circ}$ en la porción final, favorece el descenso de los $200 \mathrm{~m}$ de desnivel del umbral (b en FIGURA 7). El brusco cambio de pendiente implica la rápida detención del alud, con un brusco descenso de la presión y la velocidad que implica una reducción de la distancia proyectada. La estrechez del valle, con una contrapendiente inmediata, favorece la detención y acumulación de la masa de nieve en el fondo de valle, donde ocupa una pequeña porción (c en FIGURA 7). Las condiciones térmicas y las pendientes hacen del circo de El Hoyo un lugar muy favorable para la génesis de aludes, que dependiendo de la cantidad de nieve movilizada, puede alcanzar el fondo del valle o quedar retenido en la cubeta superior.

Una estimación inicial sitúa una cantidad de $\sim 50.000 \mathrm{~m}^{3}$ de nieve en el fondo de valle, entre 4.000 y $10.000 \mathrm{t}$ de nieve. Interpretamos, pues, que se trata de un alud que descendió $530 \mathrm{~m}$ hasta alcanzar el fondo de valle y ascender por la ladera opuesta $75 \mathrm{~m}$ y entre 5 y $10 \mathrm{~m}$ de desnivel, ocupando en el fondo de valle una superficie de 1,7 ha. Las estimaciones de velocidad indican entre 20,5 y $29,8 \mathrm{~m} \mathrm{~s}^{-1}$ en la porción final, que en las altas superarían los $50 \mathrm{~m} \mathrm{~s}^{-1}$, si bien poseen menor capacidad destructivas por su baja densidad. El alud de nieve seca y polvo genera un frente de viento, posiblemente con partículas de nieve, que impacta con menor capacidad, pero es capaz de desplazar elementos y causar daños. Este es el caso de las tejas de la iglesia, dañadas y desplazadas de abajo arriba, y sin que se depositara nieve en el tejado. También el desplazamiento de 30 metros de la techumbre del refugio, que se deposita sin daños en posición planar en la ribera opuesta del río, permite deducir un fuerte flujo poco denso que traslada el tejado en flotación, después de que la ola de presión se introduzca en el edificio y comprima el aire interior, liberándose violentamente y desplazándose en una masa poco densa de aire y partículas de nieve. Porel contrario, la porción frontal del alud constituiría un flujo denso donde la combinación de alta velocidad (entre 20 y $30 \mathrm{~m} \mathrm{~s}^{-1}$ ) y alta densidad implica una elevada capacidad de destrucción. Este flujo denso tendría en la 
porción final menos de $2 \mathrm{~m}$ de espesor, pero la presión de impacto (estimada entre 10,2 y $20,8 \mathrm{~kg} / \mathrm{m}^{2}$ ) propició el derrumbe total del refugio, el arrancamiento de raíz de los álamos, y la rotura y vuelco del muro de piedra. La destrucción de los árboles y el impacto sobre las infraestructuras permite reconstruir la extensión y la dinámica interna del flujo de nieve, que se centró en la alameda, disipándose hacia los márgenes, el sector del refugio hacia el norte $\mathrm{y}$ de los prados hacia el sur.

\section{V.2.b. Los daños causados por el alud}

Los daños inventariados en las 1,7 ha que ocupa la zona de recepción del alud fueron muy diversos (FIGURAS 8 y 9, CUADRO 3). El más grave fue la destrucción total del refugio del Club Espigüete y elementos de la parcela. El tejado se desplazó hasta la orilla contraria del río, a $31 \mathrm{~m}$ de su posición original, en perfecto estado y con la conservación de elementos como la chimenea, que como hemos señalado, apunta a un alud de flujo seco con una ola de presión frontal alcanzando el edificio. Otros daños han sido el deterioro del camino rural de acceso al refugio y todo el arbolado de la vega en la orilla derecha del río. Este ha sido arrancado de raíz, indicando elevadas presiones de impacto propias de la masa de flujo denso a velocidades que superarían en este sector, recién cambiada la pendiente, $\operatorname{los} 30 \mathrm{~m} \mathrm{~s}^{-1}$.

Se han detectado daños en el tejado de la iglesia parroquial, con levantamiento de tejas a $3 \mathrm{~m}$ del suelo, que denota un empuje desde abajo pero no el recubrimiento de la techumbre. A. Díez Riol (DIEZ RIOL, Mar 01, 2010, fotopicos.net) apuntaque la iglesia ha sufrido deterioros por aludes al menos a principios de siglo, con daños estructurales reparados en los años 50. Sin duda que estos aludes serían de mayor envergadura que el actual, pues alcanzaron de lleno a la iglesia. El de 2015 genera daños menores, si bien no se ha podido constatar si los daños son por la nieve o por el frente de viento, pues los daños son ocasionados de abajo arriba, pero no denotan la llegada de un flujo denso impactando contra el muro ni cubriendo, siquiera parcialmente, el tejado de la iglesia. En el alud señalado por Díaz Riol, la masa de nieve, o rueda según la denominación vernácula expuesta por este autor, vendría de la ladera al NW del valle, afirmación a partir de informantes locales.

Otros daños menores de infraestructuras fueron el cajetín de registro (techumbre y cable de la luz junto a la iglesia), el deterioro de postes y caída de cierres y muros en la vertiente opuesta, alcanzando huertos y jardines de las casas colindantes. El vuelco de la tapia que limita con la calle principal permite deduciruna elevada presión de impacto, mayor que en el sector de la iglesia. Las presiones estimadas (entre 10 y $20 \mathrm{~kg} \mathrm{~m}^{2}$ ) se ajustan a la capacidad de derrumbar muros, pero se aprecia como en unos pocos metros, a $35 \mathrm{~m}$ en la 
iglesia, $20 \mathrm{~m}$ en la fuente, la energía se disipa rápidamente sin causar daños. En este sector la masa de flujo denso alcanzaría $\sim 2 \mathrm{~m}$, como señalan los daños y la destrucción del ramaje inferior de los árboles. El alud se desplazó por la vertiente opuesta ascendiendo hasta la fuente y los jardines contiguos, ya sin energía para derribar muros o construcciones, pero abandonando grandes masas de vegetación, y sedimentos finos procedentes de la ladera opuesta. Todo el rellano quedó cubierto por masas de ramas y troncos, arenas y gravas transportados por el alud. Los daños causados por la nieve, con la destrucción total en la orilla derecha, y moderada a medida que nos alejamos del río, permite observar que la capacidad destructiva alcanzó los $2 \mathrm{~m}$ de altura, tronzando las ramas del arbolado hasta esta altura y derrumbando el muro de un metro.

Figura 8. Estructura de la población de Cardaño de Arriba y zona de detención del alud. Se aprecian los elementos dañados por el alud. 1, destrucción de abedules. 2 y 3, destrucción arbolado de ribera. 4, refugio. 5, muro. 6, ladera con acumulación de leñas y sedimentos. 7, poste y cables de la luz. 8, tejado de la iglesia.

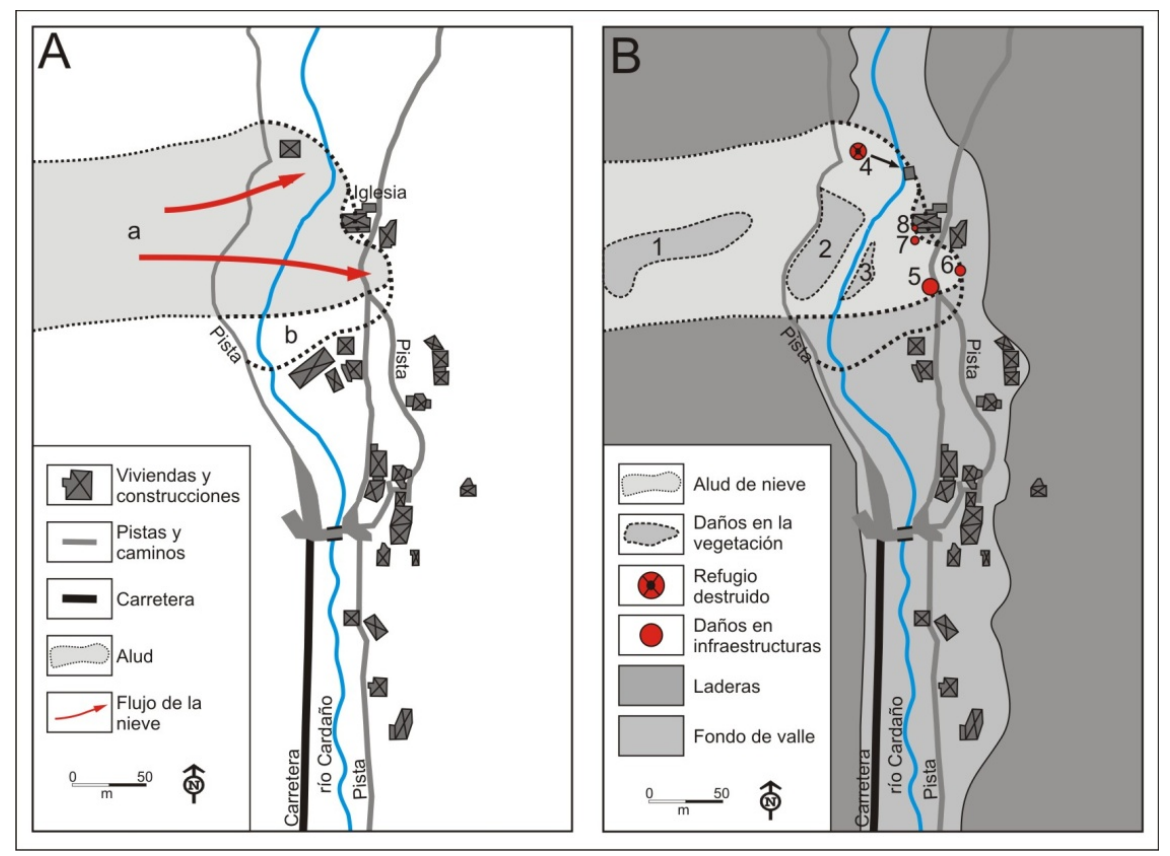

FUENTE: Elaboración propia

Cardaño de Arriba constituye un núcleo disperso en una tendencia lineal, derivada de su alojamiento en el fondo del valle, y condicionado por tanto por el medio, y en torno al camino, aprovechando los terrenos más llanos. Pero un análisis atento de la organización interna tradicional de Cardaño de Arriba per- 
Figura 9. Daños causados por el alud en Cardaño de Arriba. A, procedencia del alud y destrucción del refugio. Se aprecia el tejado en la orilla opuesta del río. $B$, estado del refugio de Club Espigüete. $C$, destrucción de la vegetación de ribera en la margen derecha del río. $D$, tejado del refugio desplazado a la orilla contraria del río. E, daños menores en la techumbre de la iglesia. F, muro derribado en el límite de la calle principal.

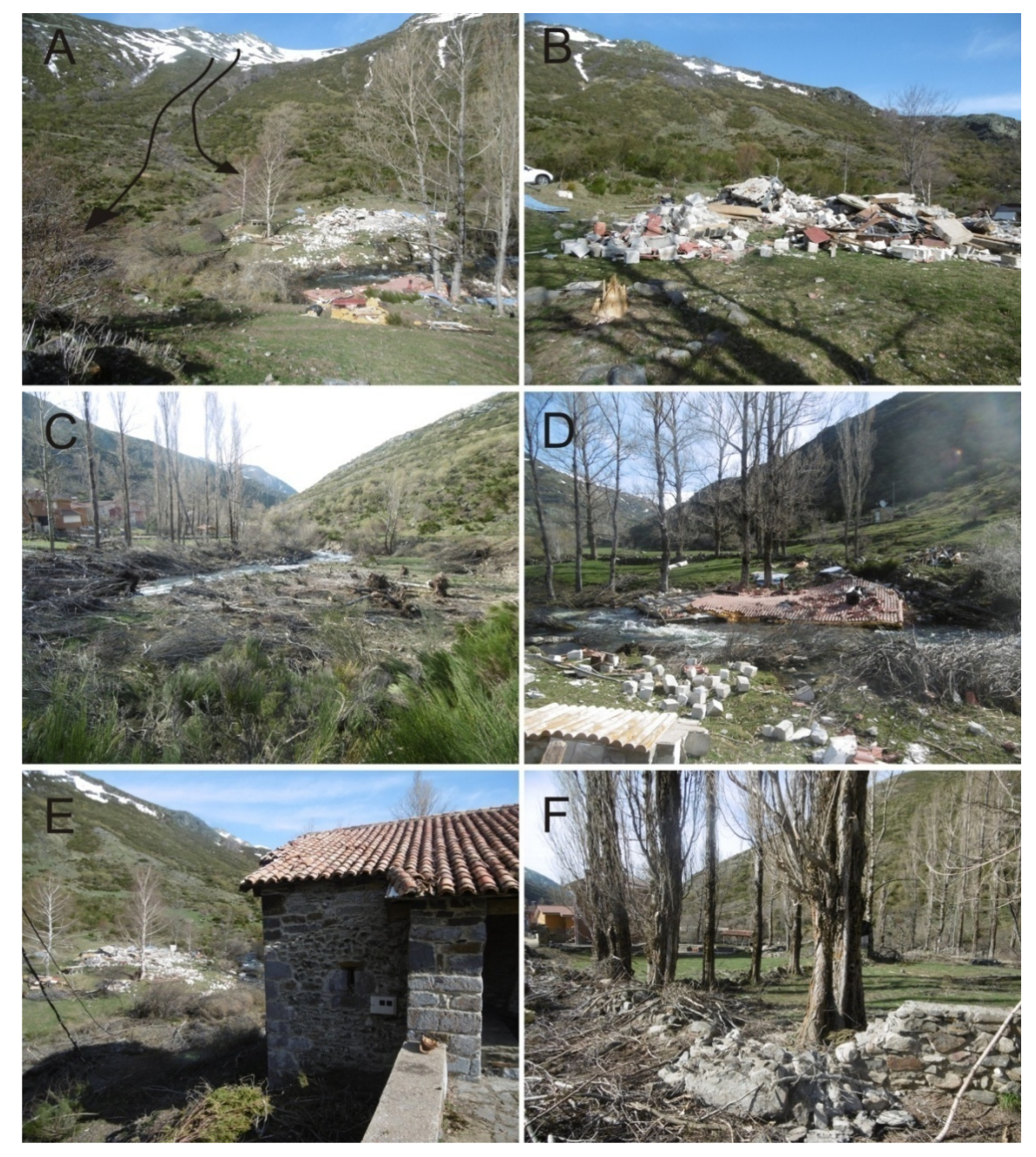

FUENTE: Elaboración propia

mite aprender algunas lecciones del sistema tradicional de poblamiento y su dominio en el conocimiento del medio (FIGURA 8). La zona de recepción del alud, que parece coincidir con el testificado por Díez Riol de principios de 
siglo, está libre de construcciones y únicamente la iglesia, construcción comunal no habitada permanentemente se sitúa en su ámbito de destrucción. Las construcciones tradicionales se ubican en la ladera opuesta o aguas abajo, ya fuera de la zona de recepción de aludes, de modo que se aprecia un círculo con tierras de cultivo (hoy pastos y arboleda) libre de construcciones, lugar ocupado por la lengua del alud. En la ribera opuesta del río, no existieron construcciones de ningún tipo, ni en la terraza aluvial plana, ni en el pequeño cono de deyección aluvial generado por un torrente procedente del Hoyo, que canaliza las aguas y sedimentos del mismo. Es en estos lugares donde se concentra la máxima capacidad destructiva del alud. Y es en este cono de deyección aluvial donde se ubicó el refugio de montaña, totalmente destruido y situado en la porción de mayor peligrosidad en relación con el acceso de aludes al fondo de valle. Este sector se verá afectado tanto si los aludes proceden de las laderas sureste como noreste. De hecho, los dos aludes conocidos de grandes dimensiones han arrasado este sector, por ser la zona de recepción inmediata al cambio de pendiente. Son estos hechos que podemos aprender, y cartografiar, los verdaderamente útiles para evitar errores del pasado y disminuir el riesgo frente a los aludes, aunque la peligrosidad siga existiendo.

\section{CONCLUSIONES}

En el valle de Cardaño se han detectado al menos cinco sectores con potencial de aludes y una elevada peligrosidad, donde el riesgo se está incrementando por el aumento de la frecuentación invernal. Ya se han constatado víctimas mortales, ligadas a la práctica del montañismo, y daños materiales a infraestructuras montañeras, pastoriles y tradicionales. En ellos, 12 sectores constituyen zonas de aludes con periodos de retorno entre $\sim 100$ y algunos años, todos ellos aludes de gran magnitud (tamaños 3 y 4, CSAS y EDSS), concentrados prioritariamente en el macizo de Espigüete (10 casos) y en los valles del entorno ( 2 casos).

Los aludes producidos en la zona de estudio durante este periodo fueron naturales, no inducidos por la acción humana, asociados a una sucesión de factores como la innivación extraordinaria, la estructura del manto nival, favorable a su inestabilidad por tener un espesor de nieve reciente de más de 1 metro sobre una capa de nieve transformada, y la entrada de un anticiclón. Todo ello implicó un periodo de inestabilidad y el desencadenamiento de sucesivos aludes de gran magnitud, así como presumiblemente, de otros muchos de menor magnitud no inventariados. Sin embargo, la excepcionalidad de los aludes no es tal, pues existen desde principios del siglo XX fuentes que atestiguan aludes previos en las mismas zonas. El estudio ha permitido caracterizar el alud de Cardaño de Arriba (CUADRO 3) y establecer los parámetros de 
velocidad y presiones de impacto que muestran la elevada peligrosidad de los aludes en el valle de Cardaño, así como los daños causados.

Durante el periodo de aludes sucedido entre el 31 de enero y el 13 de febrero de 2015, se generaron aludes de placa de tamaños 3 y 4 (escala CSAS y EDSS), definidos por su capacidad para destruir vehículos, coches y grandes camiones, o destruir algunos árboles, con extensiones de $\sim 1 \mathrm{~km}$ y presiones de impacto de más de $10 \mathrm{~kg} / \mathrm{m}^{2}$ para los de nivel CSAS 3; o capaces de destruir infraestructuras (ferrocarril, carreteras, viaductos), grandes camiones, edificios y bosques de más de 4 has, con longitudes de $\sim 2 \mathrm{~km}$ y presiones de impacto de más de $50 \mathrm{~kg} / \mathrm{m}^{2}$ para los de nivel CSAS 4 . Aunque los aludes analizados son de menor longitud y no se ajustan a las presiones de impacto, los daños causados por el alud de Cardaño de Arriba a edificios, infraestructuras y vegetación, las pérdidas económicas y el riesgo de daños personales -en caso de haber estado ocupado el refugio- aconsejan realizar estudios detallados y gestionar el territorio para la mitigación de riesgos, y su clasificación por tamaño permite situarlos en un marco adecuado que induce a tomar medidas de prevención y gestión del territorio.

La normativa internacional incide en la necesidad de disponer de cartografía de sectores de aludes en los medios de montaña, así como de limitar la construcción en sectores de riesgo o mitigar los posibles daños, pero también lo hace tanto la legislación autonómica (Ley de Urbanismo de Castilla y León BOCYL, 5/1999- ), como la local (ley de declaración del «Parque Natural de Fuentes Carrionas y Fuente Cobre-Montaña Palentina»-BOCYL, 4/2000 de 27 de junio-; y «Directrices de Ordenación de Ámbito Subregional de la Montaña Cantábrica Central en Castilla y León» -Ley 4/2011, de 29 de marzo-). Se hace necesario cumplir las legislaciones y afrontar una gestión del territorio sensible al conocimiento tradicional y la organización del espacio, donde ninguna construcción tradicional ha sido afectada por los aludes, e impidiendo la construcción en zonas de riesgo y afectadas por aludes.

La presencia de aludes tamaño 3 y 4 , y los daños causados en las carreteras, construcciones, infraestructuras y vegetación en el valle de Cardaño, aconsejan realizar estudios detallados sobre riesgo de aludes y gestionar el territorio para la mitigación del riesgo, más si cabe cuando desde la administración se propugna su fomento como recurso turístico y de desarrollo endógeno. Se hace necesario, y urgente, la elaboración de mapas de riesgos de aludes del valle de Cardaño, así como de toda la porción de la Cordillera Cantábrica, como ya han iniciado en otras comunidades autónomas. Entre otras medidas, es necesario limitar la construcción en sectores de riesgo y exposición al peligro de aludes y mitigar los posibles daños, abogando por una gestión del territorio 
sensible al conocimiento tradicional y científico, lo que hace prescriptivo levantar el refugio destruido en una localización diferente a la de su ubicación actual.

\section{AGRADECIEMIENTOS}

Este trabajo es una contribución al proyecto CGL2015-68144-R, financiado por el Ministerio de Economía y Competitividad.

\section{BIBLIOGRAFÍA}

Alonso, J.L. (1987): Estructura y evolución tectonoestratigráfica de la región del manto del Esla (Zona Cantábrica. NO de España). León, Dip. Provincial de León, Instituto Fray Bernardino de Sahagún.

CANADIAN AVAlANCHE AsSOCIATION (CAA) (2007): Observation Guidelines and Recording Standards for Weather, Snowpack an Avalanches. Revelstoke, British Columbia, Canada.

CARRERA, P. y VALCÁRCEL, M. (2010): «La acción geomorfológica del manto nivoso estacional en la Sierra de Ancares: vertiente nororiental del Pico Cuiña (León)». Cuadernos de Investigación Geográfica, nº 36, 85-98.

CASTAÑÓN, J.C. (1984): «Sobre el modelado originado por los aludes de nieve en el Prau del Albo (Alto Huerna, Asturias)». Ería, 6, 106-112.

CRUZ, J. (1987): «Los aludes o avalanchas de nieve en España». Cuadernos de protección civil, 16, 15-20.

FERNÁNDEZ CAÑADAS, J. A. (2014): Los aludes de nieve en el Macizo de Peñalara. Madrid, Nota técnica 14. Agencia Estatal de Meteorología (AEMET).

Fernández SAntos, P.; Songini, G.; HuRTAdo, R. y MinTeGUi, J.A. (2015): «Delimitación de la zona amenazada por aludes, en el área dominada del torrente de Estiviellas (Canfranc-Estación, Huesca)». Cuadernos de la Sociedad Española de Ciencias Forestales, 41, 115-130.

FurdadA, G. (1996): Estudi de les allaus al Pirineu Occidental de Catalunya: predicció espacial $i$ aplicacions de la cartografia. Logroño, GeoformaEdiciones.

GArcíA, C., RuIZ, J., SÁnCHEZ, C. y PoBlete, M.A. (2014): «El impacto del episodio avalanchoso de 1888 en el macizo asturiano, a través de la prensa», en Avances, métodos y técnicas en el estudio del periglaciarismo. Barcelona, Universitat de Barcelona, 55-63.

GONZÁlez TRUEBA, J.J. (2007): «Geomorfología del macizo central del parque nacional de los Picos de Europa». Madrid, OAPN/Ministerio de Medio Ambiente.

GonzÁlez TruebA, J.J. y SERRANO, E. (2010): «La nieve en los Picos de Europa: implicaciones geomorfológicas y ambientales». Cuadernos de Investigación Geográfica, 36 (2), 61-84.

GraY, D.M. y MALE, D.H. (1981): Handbook of snow. Principles, processes, management and uses. New Jersey, The Blackburn Press.

HERNÁNDEZ HolgADO, O. (2014): Una aproximación a la nivología en los Picos de Europa. Nota técnica $\mathrm{n}^{\circ} 15$. Madrid, AEMET. 
Julián, A.; PeñA, J. L.; Chueca, J.; Zabalza, J.; LapeñA, A. y LóPez, I. (2000): «Cartografía de zonas probables de aludes en el Pirineo aragonés: Metodología y resultados». Boletín de la A.G.E., 30, 119-134.

López Martínez, J.; CarCavilla, L.; Chicharro, E.; Escalante, E.F. (2000): «Neve e valanghe in Spagna». Neve e Valange, 39, abril 2000, 6-19.

MCClung, D. y SHAERER, P. (1980): «Snow Avalanche Size Classification»,en Proceedings ISSW. International Snow Science Workshop, (29 November 1980) Vancouver BC, Canada 3-5, 12-30.

MCCLUNG, D. M. Y LIED, K. (1987): «Statistical and geometrical definition of snow avalanche runout». Cold Regions Science and Technology, 13(2), 107 - 119.

MCClung, D. M. y SCHAERER, P. (1996): Manual de avalanchas. Madrid, Editorial Desnivel.

MONER, I., ORgué, S., GAVALDÀ, J. y BACARDIT, M. (2013): «How big is big: results of the avalanche size classification survey», en International Snow Science Workshop. Grenoble, ChamonixMont-Blanc.

PAlomo, M. (2007): «Los aludes en el Circo de Piedrafita (Pirineo aragonés): el evento del 8 de febrero de 1996». Boletín Glaciológico Aragonés, 8, 61-83.

PELLITERO, R. (2009): «Application of an alpine geomorphological mapping system to an atlantic mountain environment: The Curavacas Massif (Cantabrian Range, Northwest Spain)» Journal of Maps, 5 (1), 194-205.

PELlitero, R. (2012): Geomorfología, paleoambiente cuaternario y geodiversidad en el macizo de Fuentes Carrionas-Montaña Palentina. Tesis Doctoral. Universidad de Valladolid.

Pellitero, R. (2013): «Evolución finicuaternaria del glaciarismo en el macizo de Fuentes Carrionas (Cordillera Cantábrica), propuesta cronológica y paleoambiental». Cuaternario y Geomorfología, 27 (1-2), 71-90.

PELlitero, R. (2014): "Geomorphology and geomorphological landscapes of Fuentes Carrionas». Journal of Maps, 10 (2), 313-323.

PEllitero, R. y SERRANO, E. (2012): «La nieve como agente geomorfológico en la cara N del pico Curavacas (Cordillera Cantábrica)», en Avances de Geomorfología en España 2010-2012. SEG-Universidad de Cantabria, Santander, 633-636.

PUENTE, J.M. (2006): «La Gran Nevada de 1888 en Cantabria y Asturias». Revista del Aficionado a la Meteorología (RAM), nº46.

RoDÉS I MUÑOZ, P. (1999): Análisis de los accidentes por aludes de nieve en España: Una aproximación a la revisión histórica. Barcelona, Ergon.

RODÉS I MuÑOZ, P. (2012): «Accidentes por aludes de nieve en España durante las diez primeras temporadas del siglo XXI». Revista de l'Associació per alConeixement de la Neu i les Allaus, 4,19-23.

SAntos, J.; REDONDO, J. M.; Villar, A. G. y GutiéRREZ, B. G. (2010): «Los aludes de nieve en el Alto Sil (Oeste de la Cordillera Cantábrica, España)». Cuadernos de Investigación Geográfica, 36, 7-26.

SANTOS, J.; REDONDO, J.M.; GÓMEZ, A. y GonZÁLEZ R.B. (2010): «Dinámica actual de los nichos de nivación del Alto Sil (Cordillera Cantábrica)». Cuadernos de Investigación Geográfica, 36(1), 87-106.

SERrano, E. y Gómez Lende, M. (2015): Periglaciarismo, nivación y glaciarismo cuaternario en Alto Campoo (Cordillera Cantábrica), en Guía de Excursión. $V$ 
Congreso Ibérico del IPA. GIR PANGEA, (Valladolid, 24 al 26 de junio 2015), Valladolid, Universidad de Valladolid. En línea: http://www5.uva.es/gir_pangea/wp-content/uploads/2015/01/GuiaCampoo1.pdf.

StATHAM, G. y MCMAHON, B. (2004): «Avalanche terrain exposure scale. v.1-04. Parks Canada Agency». En línea: http://www.sunrockice.com/docs/Avalanche $\% 20$ Terrain $\% 20$ Exposure $\% 20$ Scale $\%$ 202007.pdf

VADA, J. A.; Frochoso, M., y VILAPLANA, J. M. (2012): «Evaluación y cartografía del riesgo de aludes en el camino PR-PNPE 21 de acceso a la Vega de Urriellu, Picos de Europa (Noroeste de España)». Cuaternario y Geomorfología, 26 (1), 2947.

Vada, J. A.; Frochoso, M., Rodríguez Velasco, J.J., Mediavilla, A., Hernández Holgado, O., Sanz Moral, M.P., González Pellejero, R. y FurDADA, G. (2013): «Análisis del alud del 8 de mayo de 2012 en los LLanos del Tornu. Macizo Central de los Picos de Europa». Neu i Allaus, 5, 4-11.

WOZNIAK, E. y MARQUÍNEZ, J. (2004): «Evaluación de la susceptibilidad por aludes a escala regional: el caso de Asturias», en Riesgos Naturales y Antrópicos en Geomorfología, SEG. CCM (CSIC), Madrid, 95-104. 